\title{
The Possible Place of Relevance Theory in a Cognitive Explanation of Literature
}

\section{José Luis Guijarro University of Cádiz}

\begin{abstract}
The concept Literature is a complex one. Relevance Theory can describe in a cognitive and scientific way its communicative operations that do not distinguish it from other types of discourse in a fundamental way. What is urgently needed is a cognitive scientific approach to the artistic aspects of this concept. In this paper, a possible way is offered in outline.
\end{abstract}

\section{Introduction}

It is not uncommon, at the end of an introductory seminar on Relevance Theory (henceforth, RT), for members of the audience to ask questions about the potential of the theory as a means of explaining literary communication or, for short, Literature (not less!). Usually, this sort of question makes the lecturer wince and may cause him to turn nasty. Small wonder that when the lecturer answers the question (which, being a conscientious academic, is the right thing to do) the person asking the question is left without a satisfactory explanation. ${ }^{1}$

The problem is that we seldom think of theories as parts of integrated world views. After all, theories are devices to solve scientific problems of specific domains, and as such, RT purports to handle questions on communicative aspects of human interaction from a cognitive point of view. ${ }^{2}$ It is all very well to use that theory as a means to clarify linguistic (and pragmatic) problems which have been poorly understood in the past and can now be solved in easy and elegant ways; I am sure that this is what its creators had in mind when 
they set out on their brilliant task, and the papers in the present volume are clear proof of that effort. However it is perhaps more difficult to handle all the variables that define a complex phenomenon such as "literature" by concentrating only in the cognitive and communicative aspects that RT so clearly describe. ${ }^{3}$

My purpose in this case is to try and give my own integrated view on the important, but not exclusive place RT has in understanding a complex phenomenon like the one we call Literature. In order to do that, I will have to set what for me is a convenient stage, arrange the lights in order to illuminate the issues I believe to be important, and give what I consider to be the crucial factors their role in the play as I experience it. It is my contention that if all goes well, people who are interested in such questions as I mentioned above -that is to say, philosophers, rather than linguists- might well be given an indication of how RT integrates in the scientific thinking opened by cognitive research in fields that seemed intractable until now.

\section{The evolutionary stages of human thought. A Science-fiction story}

Since I am preparing a play for you, it will not matter very much, will it, if I use some ideas that are not totally flawless but which can help us to set the stage in an easy and understandable way? As Sperber $(1984,1990)$ often asserts, even (partially) wrong or unclear notions can help us to expand knowledge and arrive at coherent and correct world views. The ideas I am going to use and adapt to my present purpose are from Horton (1982). ${ }^{4}$

It is perhaps not unreasonable to see living beings as information processing devices, that is to say, animals in general need to have some means of interacting with their environment in order to survive. ${ }^{5}$ First let us assume that human beings are animals which belong to the bighest step of the evolutionary ladder -I hope this assumption will not give rise to disagreement! Now I want to tell the (science-fiction) story of the evolution of the human information processing device from the moment when it was more or less similar to that of the superior animals to its present and unique human state.

It seems a fact that the first information processing device developed by humans looked no different from that of other superior animals. As inputs it used the potentially observable objects of the world, and applied some easy inferencing rules of the type, if $X$, then $Y$ (where $X$ and $Y$ can be any of a number of objects) to give outputs which in turn helped survival and propagation. For instance,

If every time [if I come close to a lion, then the lion tries to eat me up] then I had better not come close to it -or if I do, I had better have something with which to defend myself.

The limits of this way of processing are "specific" -we cannot process reality as a fly or as an elephant.

The next step in evolutionary history was Man's (and woman's) ability to use objects created in the mind as inputs, that is to say, things not necessarily observable by the senses. 
This gave us human beings an immense power of prediction, for the rules applied to those invented objects were still of the same inferencing type as the one above. For example,

If every time [if there is a tempest at sea, then our boat may capsize [if my boat capsizes, then I drown]] then I pray to Neptune [if everything has a creator, then tempests at sea have a creator whose name is Neptune] so that he saves me from drowning.

Notice that there are many unwarranted assertions here (e.g. why is the creator of the tempest's name Neptune?) that we possibly don't share. We did share, though, all the hypotheses appearing in the first type of information processing; that is precisely why I said that the limits of that first type of processing were specific. The limits of the information processing that we are now looking at, however, are not specific (otherwise you would share them!). Let us say they are social -or cultural, if you prefer. If one shares them, one belongs to the "in" group; if not, one is an outsider, or, even worse, a wicked apostate. Either way one might as well be destroyed as a dangerous heretic -remember Galileo?

The last step in our processing device is the one adopted very recently. The input might be still constituted by objects invented in our minds, but the inferencing rules must use only observable (material) facts. This is a very difficult requirement to follow, but since the processing device is chosen individually, it is the individual who sets its limits in a conscious way. I will not give examples of these operations now, for the paper is really concerned with the workings of such a system trying to arrive at an invented unobservable notion we have named Literature.

Before proceeding any further, let me point out that the first way of processing is as old, if not older than our species, and can therefore never be obviated. The second one is very old too and well established in our mind. It is very difficult not to assert unwarranted cultural acquired notions if we know that a large body of human beings share them. Some of them might appear to be simple facts, ${ }^{6}$ that is to say their limit seems "specific" and not "cultural." This last way of processing, however, is a very difficult one to follow and a concerted effort must be made not to fall into the other two very natural ${ }^{7}$ ways. We may now agree that those three ways of processing information are what we commonly term, ways of thinking. The first one corresponds roughly with what we know as common sense, the second could be called traditional thought, and the last one, scientific thinking.

As we all know, there are consciously established limits that constrain scientific thinking in a strict way. Let me point to two sets of requirements. The first set was designed by Noam Chomsky in his first papers on linguistics in the early sixties and the second is David Marr's requisites which appeared in his papers on visual perception, in the late eighties.

Chomsky asks scientific researchers to reach at least a first level of adequacy in their thinking: they must know what object or phenomenon they are observing. This is the level of observational adequacy. Then, they must try to describe the object or phenomenon being observed, and if this is managed, they will have reached the level of descriptive adequacy. Real scientific thought is not achieved unless this level of explanatory adequacy is reached: the level where one is able to describe the operations in a materialist causal way, which is, as I explained before, what scientific thinking is all about. However, this last level is so 
difficult to reach, that we need a new set of levels in order to clarify what the process is about.

Marr expects the cognitive researcher to be able to establish three sublevels in this explanatory state of the scientific theory. ${ }^{8}$ First of all, one must be able to establish the computational description of the phenomenon, stating what its inputs normally are, and what operations are to be applied in order to obtain the desired outputs. The first level is the most general one. In the next level, one tries to find out what kind of representations are current in the realization of those operations described in the first level - this is a cultural level of analysis. The last level, the implementation level, is the effort to understand how the general computations of the first level, and the representational level are implemented in the world. Let me give you an example from Hutchins (1997). Suppose that your object of research is human navigation. The computational level would describe the necessary operations one has to effect from the state of not knowing where one is (the input), to the state of knowing the position one has and the direction one has to follow (the output). At the representational level, it is clear that western representations on navigation are not the same today as the ones present before the compass was invented. The fundamental questions are the same, but the way each culture solves them is different. The implementational level would be the level where one would analyse those implements (from the compass to the charts) which somehow embody the representations of a special culture.

My Catch 22 question is: could one think about literature in a similar constrained way to that which Chomsky and Marr consider to be scientific?

\section{The problem of representations}

The cognitivist framework operates on two basic notions: representations and computations. In any cognitive system (a human mind, a computer, or whatever) some sort of representational input is transformed into a representational output by the workings of certain sets of operations which have to be described algorithmically. This is what constitutes the computations of the system. Let us now first look at the notion of representation.

The problem is that we do not have a clear idea of what a representation really is; what we do have is an intuitive hunch: to re-present, at least in its etymological sense, seems to point to a new presentation of something, perhaps in some other form and/or medium. If I meet a new colleague and she makes some kind of impression on me, I represent her to myself in order to approach or avoid her, whatever the urge may be. It is clear, however, that this intuitive notion does not embrace what I would like to call, perhaps inappropriately (see below), abstract representations such as, say, patriotism, marriage, literature, etc.

There are more sophisticated definitions, of course. Rivière (1986) argues that representations are micro-states of the brain (i.e., physical structures of neurons) which get translated phenomenologically (i.e., present themselves to our consciousness) as psychological states with some kind of mental structure. It may well be that these mental 
structures have the biological purpose (a) to finish the process of abstraction begun by the perceptive organs and their operations, and (b) to create objects (and relations between them) so as to predict future action. With the last part of this description, we at least have a hook to hang such abstract representations as I mentioned before -those that were never present in the world before being re-presented in our minds.

Sperber and Wilson (1986) say that representations are (structures of) hypotheses about the world we entertain in our minds. This also includes the possibility of representing abstract objects that don't exist outside.

Fair enough, but... is that enough?

Maybe we should also try to understand what these representations really mean -their content and what their shape and form might be. As for their content, Papineau (1987) believes that there are two main types: the content of representations that form beliefs, and the content of representations that constitute desires:

The biological function of any given belief type is to be present when a certain condition obtains: that then is the belief truth condition. And, correspondingly, the biological function of any given desire type is to give raise to a certain result: that result is the desire's satisfaction condition. (p.64).

It is understood that beliefs and desires are two different types of representations. This distinction, then, is one of content: truth conditions for beliefs, future satisfaction conditions for desires. ${ }^{9}$

Now, as far as the form of representations is concerned, Rivière (1986) believes that we can distinguish two basic forms:

(1) Representations whose components have the same, or similar, structural relations to those of the real world (e.g., the my friend's face has the same components, in somehow the same relationship inside my mind, as in her real face). He calls these analogical representations, intrinsical, since relationships do not have to be explicitly expressed. Obviously examples are images of any kind, not just visual ones.

(2) Representations where these relationships have to be explicitly shown, that is to say, extrinsic. These representations which are what we generally call "propositions." For instance, if you try to represent my friend's face in a proposition you will have to state if her eyes are low or high in relation to some other component, if her nose is deviant or not, and so on. As far as I know, abstract representation (e.g. love, history, creativity, greatness etc) are not so much abstract as only propositional.

There is a further distinction that has to do with the scope of the representations. Sperber (1984) suggests that there are representations which belong to individual minds, and are therefore private representations, whereas those representations that are shared by two or many more minds (i.e., a whole culture), are public representations. Communication is the process by which human beings convert a certain set of private representations into public representations by means of certain computations. Of course, public representations have to be translated into private representations in the heads of the participants, something that is almost never completely achieved. Take for instance, the representation of Literature. 
People that belong to our culture agree roughly on some kind of representation with a given content and a propositional form (i.e., "Literature is this and that, etc."). But do we all share the hypothesis that belong to our private representation of literature? I suppose this is a very difficult question to answer, but my guess is that we don't, otherwise there would not be different opinions on what literature really amounts to. ${ }^{10}$

\section{How do we "observe" representations?}

For cognitivists, then, representations are the only units worth studying scientifically. As our aim here is to try and decide if Literature can be dealt precisely in that way, we will have to characterize it in representational terms.

Literature belongs to that macrofield of thinking that we loosely name humanities. Now, cognitivists would argue that the kinds of representations humanists are normally concerned with are:

(1) What human behaviours represent. For example, talking, playing, cooking, hunting, etc.

(2) What the result of these behaviours represent. For example, a book, a dish, a building, etc.

(3) What the way in which some of those results are viewed represent. For example, a poem, a birthday cake, a special uniform, etc.

Notice that all these representations have in principle the dual status private and/or public.

You may have a certain representation of the behaviour that you consider writing has, as opposed, say, to the behaviour that you consider painting, or scribbling has; a book, as opposed, say, to an article or to a picture; or a poem, as opposed, say, to a landscape or a narrative. And you may believe that this representation of yours is, as a whole, publicly held by some other people.

Humanists, however, tend to forget the private character of these representations and assume without further ado that their own "private" representations are "public" without any relevant ${ }^{11}$ difference between the two. They then proceed, as if that object (i.e., the public representation), was something real, and begin building (structures of) hypotheses upon it, some with great ingenuity and sophistication. Ultimately, humanists end up with theories on concepts that are not even clearly (not to say causally and materially) defined. It is as if someone starts with an internal representation of some personal experience, and then pretends that (s)he has a scientific point of view of it because (s)he is able to build up a marvellous (structure of) hypothesis on its constituent parts, its functioning etc. This is what the so-called scientific structural approach to human behaviour (anthropological, linguistic, etc.) has splendidly done this century, creating a vast amount of theories that can hardly be disproved since they do not rest on any solid ground. The only way to oppose one of those 
very clever theories is to create another with even more ingenuity and sophistication. But none represents an explanation of any real problem existing outside our own minds. ${ }^{12}$ They are indeed hanging on thin air -and that is to say a lot! Dennett (1995) calls these representations skyhooks. You hang a word with a vague private meaning of your own from one of those hooks and then you construct a beautiful theory to hang from it ... an insubstantial impossibility since, as we all know, nothing cannot hang from the sky. So, where does such a theory get us in the end? Of course, these skyhooks also exist outside the structuralist world -but their creators at least do not enthusiastically pretend to be scientific; theirs is a different pretension, boasting instead of belonging to the world of human creativity and greatness.

The moral of my story is that we have to come down to earth and abandon skyhooks if we really want to think scientifically about such matters; that is to say, we have to be very careful when choosing our objects of study and should find out what their exact nature is. Moreover, we have to be aware that certain representations are so private in nature, that even when they become public, they never lose their private character. When, for instance, we think that $\mathrm{X}$ resembles $\mathrm{Y}$, it is because we privately process for our own benefit some aspects of $X$ that we think match, in a certain way, some aspects of $Y$. It would be astonishing though, would it not, if somebody tried to study resemblance in general. So, when I come across similar academic papers on "humanistic" topics, I am filled with a strange feeling - a strong sense that they are wasting their time and... ours, too!

Now, if Chomsky is right, ${ }^{13}$ and I think he is, another very difficult topic to study scientifically is "behaviour." Nobody would want, I suppose, to indulge in the construction of a learned framework on the behaviour of my dog eating all sorts of rubbish in the street and refusing the dog food I so kindly leave for its dinner. What a zoologist might probably want to know, however, is what might the causes for that type of behaviour be -not the actual behaviour by itself. In other words, as scientists we are interested in material causes of phenomena; and since the objects hanging from skyhooks have no known causes (material or otherwise), they are not objects for scientific thinking. The only point of some of the longer-surviving sky-hanging objects in our culture (or any other), is that they offer us a (possible) goal we might want to analyze in causal terms; they may prove useful in offering new insights and, especially, an explicatory ladder going from the very simple material causes to the notion that has remained unexplained until now.

We will concentrate now on the object Literature hanging from a well established skyhook in our cultural background. What is Literature? We might agree from the very beginning that literature is some sort of discourse. Now, discourse is the behaviour human beings effect in their communicative efforts among themselves. RT is the cognitivist account on how the causes of such a behaviour could be described and explained. Clearly in a volume, such as this one, specifically dedicated to solve communicative and linguistic problems by means RT, it seems clearly unnecessary and superfluous to even hint at an explanation of how RT works. However, while running the risk of stating the obvious, let us just remind ourselves that human discourse is the behaviour that comes about when human beings ostensively want to make manifest in different degrees a certain set of 
assumptions. We may further remember that the degree of manifestness is sometimes the cause of poetic effects. ${ }^{14}$ This is all that can be extracted from the theory in this aspect. It is understood that poetic effects alone do not give rise to literature or to a literary discourse. One thing we have to be clear about is that in this respect there is almost no distinction between "normal" and "literary" discourse.

We will have to make an effort and try to characterize Literature in a more precise manner. Since it seems that most cultures distinguish between two kinds of discourse, ${ }^{15}$ and if this distinction is not to be explained crucially by the poetic effects human communication sometimes achieves for all sorts of reasons, there must be something more. To make things easy, we can begin our search hanging Literature from another skyhook, namely Art. And start anew trying to figure out what this object really (i.e. casually) is. So, having accepted that Literature is an act of human communication causing a behaviour we call discourse, let us now try to understand something about what we mean when we characterise this discourse as being artistic.

\section{What are we "observing" when we talk about $A r t$ ?}

This is indeed a tough question. Some believe that when one talks about Art one is thinking of the objects that make up the inventory of some worldwidely accepted human creativity: pictures, sculptures, books, photographs, films, musical scores etc. For them, therefore, $A r t$ is in the objects themselves. Others prefer to think about human creativity in general and concentrate on what artists try to do when they paint, write, or dance. For these people art is in the action of the artists. There are even others who believe that $A r t$ is in the "eye of the beholder," in the reception of the messages artists produce. For them, Art is in the action of the interpreter(s). We may also believe that art is both, action from the part of the artist and the receptor, and the object that embodies the artistic message, and then try to study the "object" art as a mixture of activity and result of that activity. ${ }^{16}$ Let me propose a different approach.

Suppose we characterize Art as an attitude. An attitude is previous to action and, obviously, to the results of that action. Good so far, but you may well ask: What is an attitude? Psychologists have difficulties in defining what a human attitude really amounts too; let me then simplify the problem by accepting the very clear notion of attitude defined by Sperber and Wilson (1986). For them, an attitude is a way of processing information. No more and no less. In human communication, the participants are aware that there are different ways of processing the same propositional forms in order to get the message straight. If I say a simple sentence like I will come tomorrow, my attitude, which has to be deduced (by elements in the situation, my tone of voice or whatever), may be interpreted as a threat or as a promise; or if I assert that Tony has always been a very clever guy, you may notice that I say it with an ironic or even sarcastic intention. There are, of course, ways to make these attitudes explicit in human communication by embedding propositions in socalled performative propositions, or, to be more exact, high order propositions. What 
interests us, is that we do not process the information in the propositions expressed in the same way, if we assume there are different attitudes in the utterances.

For all I know, Art (and one of its manifestations, Literature) is the processing of information in a special way which will have to be described. Even a WC basin can become art if we adopt a certain attitude with respect to the information we can extract from it in special circumstances, as modern artists well know.

\subsection{How do we "describe" Art?}

I will assume that you are going along with me in my thinking and accept, at least in principle, that $A r t$ is an attitude or, in cognitive terms, a way of processing. Now let me try the second movement and describe this way of processing, albeit in a partial intuitive way. Sperber and Wilson characterize human communication as a process whereby new information is put in contact with old information stored in our minds in order to produce the desired effects. These desired effects, then, depend on the relevance the new information shows for us in a given moment.

My question is: how does a new born baby find relevant information when it does not have any other information in its mind? One can argue, I think quite rightly, ${ }^{17}$ that there is innate information stored in the minds of new born babies which could then act in the way Sperber and Wilson suggest. But it might be slightly different if we believe that part of this information stored from birth, operates in such a way that the first information which comes from the outside gets imprinted in the mind, creating what Fodor (1983) calls a module -i.e., a device to process information in a certain fixed way (language might be such a module). Sperber (1994) has a different story for modules which neatly fit my idea. For him, modules are not only imprinted or otherwise fixed at the beginning of human life; he thinks human minds do not stop creating modules during the whole of their existence.

We could perhaps say in an impressionistic manner that the creation of those modules is in fact the building up of what we know as human personality. The fixing of some way of processing the information that comes from the outside, be it from the sounds of a human language or of any other type of information, does indeed characterize us in many important aspects.

My claim is that, in some special cases, humans are not only programmed from birth to develop processing modules, but can adopt an attitude which facilitates the building up of such devices. We have all heard of the long practices that some "religious" movements establish in order to reach illumination of some kind or other. In our culture, for instance, lack of sleep and food together with long prayers, which through repetition and repetition loose their communicative effect, achieve states of mind where the information stored in the brains, or at least some of it, is not recovered so as to process the new information that keeps coming in. If you go on long enough, so some claim, you might all of a sudden "see the light" -the information coming from the outer world in a new and brilliant (?) way. In the Japanese Zen culture, the blocking of the normal pace of information processing using stored information to interact with the new is achieved by the koans -meaningless sentences 
which the Master constantly repeats for his pupils' benefit. There are other means in other cultures, as we all know. The important common thread is that they all try to stop using old information in order to process new incoming information in a relevant way. The mystics assert that this way of seeing reality is the only real way. As the Zen dictum says:

When you start your way of Zen, the mountain is a mountain. When you go along the way, the mountain ceases to be a mountain. But when you arrive at the satori (illumination), the mountain IS the mountain.

Now, I do think that the deep sense of the attitude that I want to describe as Art is precisely a manner of processing information which has a lot to do with the mystic attitude. In former papers ${ }^{18}$ I pointed out that the notion of $A r t$ as being subjective, could be explained in these terms: the subject experiences reality directly, without using any model (or object) prefabricated to handle or understand reality -which is what scientific thinking tries to achieve by being objective.

As Sperber and Wilson explain, attitudes can be inferred by using all sorts of indices; but they can also be decoded from the high order propositions which sometimes explicitly embed linguistic messages. The attitude I have described as the true embodiment of the notion of art can also be inferred or decoded as the case might be. We have all sorts of indices that allow us to process some type of information in the "subjective" manner, some of which are so strongly manifest that they approach the decoding process. ${ }^{19}$ For instance, if we see a broom hanging from a wall in a museum, we have a very manifest indication that it is to be treated as art, and not as a tool abandoned by the cleaning staff.

At this point of my description, there may be many who oppose strongly to the idea of art as a mystical attitude and experience -and they are probably right, for this attitude cannot be the whole story. Indeed, for most of us $A r t$, is an experience that needs a lot of cultural background in order to be appreciated in a convenient way. So, where does the idea of not using stored representations go? I will certainly have to develop this idea further to reach a more general account of what the artistic attitude really is.

\subsection{How do we "describe" artistic communication?}

I believe that the essential description of $A r t$ is the one I have just outlined, but we are born in a society of human beings which communicates constantly for all sorts of differing reasons, and as I said before that Literature is a kind of communication, but what kind of communication?

I will adapt some of the ideas of Pratt (1977) to the present framework. According to her, the gist of artistic (and literary) communication can also be defined as a human attitude, or, alternatively, as a way of processing information. We may process information in a direct way, trying to create and/or get the message that is more or less explicit in the means (linguistic or otherwise) we use. But we may also have a high order attitude with which we value this message in some way. That is, in Pratt's words, we can display the message in order to watch it as a representation worth considering. If this is so, artistic communication 
in general, and literary communication in particular, have a further component of great importance: the social value a given culture bestows on some of these displays which Pratt is talking about.

\section{Where to look for scientific "explanations":}

As this is perhaps not a very extended representation, let me try to recapitulate what I described so far. It is my contention that Art (and Literature) can be defined as a complex of two basic human attitudes and the description of these attitudes must account for the following facts: (i) that one of them permits us to try to perceive reality in a direct way, with as little interfering schemes of stored hypothesis as possible. As this attitude is what gives art its subjective character, I will call it subjectivizing attitude. (ii) that the other attitude is the one that allows us to display information wholes in order to judge them in some individually and/or socially established manner. This is what makes art a communicative phenomenon. We will call it displaying attitude for obvious reasons. What we now need is an explanation of why human beings have the possibility of processing information in such a peculiar ${ }^{20}$ way and, also, when and how they use it.

I have no biological explanation for the subjectivizing attitude, but I can loosely advance a working social hypothesis by pointing to the fact that, apart from new born babies, the processing of information with the minimum interaction with stored information seems to occur automatically in certain moments of human life. Another such moment could be when the individual finds a mate. Everything is "logically" against this mating, but there you are, it's love at first sight. One can do nothing about it! I hope that the shallowness and banality of this explanation does not obscure the real possibility of pointing to a socio-biological function for this way of processing. In other moments of great emotion (fear, anguish, delight etc) this way of processing incoming information seems to function as well and "form" the personality of the individual who went through it. One may hear, for example, that so-and-so changed since he came back from the War. Among other explanations, the subjective contact with the information provided by the world in such special circumstances may be worth investigating further. If it proves to be right, we will then have a real explanation of the effects $A r t$ sometimes produces.

The displaying attitude is easier to trace biologically (and socially! Cfr. note 22). As Pratt claims, it enhances the social network, enabling people to share feelings of solidarity -an important cohesive factor for our social species. It therefore has a clear selective value. Of course, the representations people want to share and value form part of the three systems I have tried to describe above: species-specific, social and individual. It seems that speciesspecific possibilities are arousal-raising and arousal-moderating devices, such as those pointed out by Berlyne (1971: 254):

The arousal-raising capacity (...) depends mainly on information content, complexity, number of subunits and details, and richness of ornamentation. (...) Similarly, arousal 
moderation depends in large measure on redundancy, of which there is a great deal whenever (...) importance is attached to symmetrical or otherwise restrictive structure.

The social possibilities depend on acquired patterns in cultural evolution. Some societies, like our modern Western one, may value innovation, others, the repetition of explicit cultural structures, as apparently the ancient Egyptians did, and others, like the people in the Renaissance, strive to recover the cultural patterns of ancient cultures. There are also cultural areas that are fashionable in one culture and forgotten in others, etc.

It is of course very difficult to point to individual interests in general. The previously mentioned Berlyne tries a classification of what for me is of dubious value, but which may interest statistically-minded researchers (Cfr. Berlyne (1971: 255-265)).

I do hope I have been able to convey the idea that a real possibility does exist of reaching the three levels of adequacy in theorizing scientifically over propositional representations such as Art and Literature. Let me attempt to end this essay by characterizing the manner in which we might treat this topic in a scientifically cognitive way.

\section{The computational level of analysis}

According to Simon (1981:153), "solving a problem simply means to make the solution transparent." If we now want to solve the computational problem that $A r t$ and Literature set for us, we must first represent a notion of computation extended enough to comprehend operations happening inside the heads of people and those that may be found in the social system itself - what we normally call, culture. This idea is from Hutchins (1996), for whom,

"Computation [may] be taken, in a broad sense, to refer to the propagation of representational state across representational media" (p.118).

In studying Art and Literature then, we are interested in the patterns of certain elements which can be interpreted as representations in a given medium; in the way such representations go from one medium to the other. Now, what can these patterns be?

The answer, for the moment, can only be a very intuitive one. It could go like this: On the one hand, human beings are part of a physical and social environment. Physical environment is perceived and represented by the processes we outlined at the beginning of this paper, that is to say, human beings learn to deal with the physical world by creating mental representations of its relevant aspects. Social environment, however, is not as obvious to perception as physical elements are. Human beings are of course sensitive to some social interactions from almost as soon as they are aware of the physical shapes and laws that govern the physical world. For instance, they immediately learn that their mother is the helping social partner vital to their needs. ${ }^{21}$ In any case, even a social relation has to be mentally represented in some manner in order to be of any help for the individual. Let us suppose that these representations (the physical as well as some social ones) are stored 
directly as factual representations. ${ }^{22}$ They would form the gist of what I called primary thinking (or common sense) above.

On the other hand, as we also mentioned before, human beings developed the faculty of embedding representations into other representations, thus creating an immense quantity of mental elements which became the proper objects of secondary thought. What can the evolutionary benefits of this extended mode of processing information be? At first glance, dealing with real aspects of the world in an appropriate way is clearly an asset for survival, but dealing with imaginary representations which do not exist out there in the actually perceived world seems to be a hindrance rather than a help to survival. With all those dangerous creatures trying to destroy us or with all that (material and spiritual) food waiting for us, it seems such a waste to start imagining non-existent objects which keep us busy instead of running away from foes or grasping edible fruits of all sorts. Perhaps a good answer to the problem of the selective value of secondary thought lies in the following idea:

It deals (almost from the child's first talk...) with the stuff of human action and human intentionality. It mediates between the canonical world of culture and the more idiosyncratic world of beliefs, desires and hopes. It renders the exceptional comprehensible and keeps the uncanny at bay -save as the uncanny is needed as a trope. It reiterates the norms of the society without being didactic. And... it provides a basis for rhetoric without confrontation. It can even teach, conserve memory, or alter the past (Bruner, 1990: 52).

Imagination, in general, serves this social assimilation process by adapting individuals to their material and social world in a smooth way, eliminating potentially destructive processes of illadaptation. And precisely because the individual is intimately aware (most of the time) that the products of his imagination are not factual information, (s)he uses a different means of processing them -displaying them so (s)he can watch and eventually judge if they are in any way useful or not. Naturally, all this is hardly a conscious procedure. What the individual does seem to feel is a certain "peace of mind" that may help to accept difficult material and social constraints.

It is likely that in cases where these constraints are felt by a whole human group the imagination of one of its member may serve as a "peace maker" too, if it can be properly communicated. And if the other members of the group come to value this narrative and accept it as displayed information for their benefit, it may even become an idiosyncratic product which slowly turns into a "tradition" for that group. It is in that sense, I believe, that the last part of Bruner's quotation above is to be understood.

The patterns interpreted as representations in a given mind could probably be distinguished in the following terms:

A) On the one hand, the unproblematic representations. Namely those that belong to what we could loosely call the content of the representations, keeping in mind that there seem to be two types of these representations: the facts and actions of an external world (real or imagined), and the mental events in the mind of the protagonist(s). ${ }^{23}$ These two types can appear together, for instance, in the narrative, where the important 
element in a narrated imaginary world is the way the protagonist(s) interpret the world. Sometimes, however, the weight of one of these types of representations outbalances the other type as, for instance, in lyrical poetry.

B) On the other hand, the problematic representations. Those that belong to the evaluation world of the participants. I call them problematic because, as I said before, in cognitive theory there is a tendency to consider that representations belong only to the first group, while the second group consists really of procedures which indicate the way one should operate with representations. I am not sure if procedures would be considered representations in all instances, ${ }^{24}$ but I conceive them as somehow ingrained in human minds -just as representations are. These evaluative representations would frame the content representations in such a way that the whole message might be considered as displayed and, thus, prepared to be socially valued.

As was said above, a computational analysis has to account for the way such representations go from one medium to the other; how private representations made up from perceptions of the world and of private representations that interpret these representations become public representations, and are therefore capable of turning into private representations yet again in the minds of the people that perceive and interpret them. If we agree that this computational process is what we call human communication, it seems clear that RT might well be a device for analysing its operations in an explicit and coherent way. However, there seems to be more to it than just human communication. For one thing, public representations constrain, not only the content, but also the form of the likely material concerned in these operations. Let me quote Bruner again:

...The language of skilful narrative differs from that of skilful exposition in its employment of "subjectivizing transformations." These are lexical and grammatical usages that highlight subjective states, attenuating circumstances, alternative possibilities (id., 53)

We should investigate if this idea is correct, and if more constraints like these are to be found and may be explicitly described as cultural (or perhaps even as biological) processes. This field of research is one of the ways I see to expand our knowledge of what literature really is. Especially, if those "subjectivizing transformations" and other similar devices are evaluating representations which trigger the displaying mode of processing information. But there is still another field closely related to this, namely, the one that traces the passage of representations from a given medium, say, the private mental one, to another, say, the public cultural one, and vice versa. A very interesting starting point for this analysis is Dan Sperber's sketch of a theory which he calls the epidemiology of representations (Sperber, $1984,1990,1994$ ) or the contagion of ideas (Sperber, 1996) which can be summed up here with his own words:

An epidemiology of representations is a study of the casual chains in which [the] mental and public representations are involved: the construction or retrieval of mental 
representations may cause individuals to modify their physical environment, for instance to produce a public representation. These modifications of the environment may cause other individuals to construct mental representations of their own; these new representations may be stored and later retrieved, and, in turn, cause the individuals who hold them to modify the environment, and so on. ${ }^{25}$

\section{The representational level of analysis}

At this level, one should find out what sorts of attitudes, beliefs, behaviours and actions are considered by different societies to embody the computational processes I have tried to outline above. For instance, there are societies where these processes are not managed in written media and constitute what some very aptly call oraliture. ${ }^{26}$ In those oral cultures, the representations of these processes, which may include the social instances in which they are enacted, the accepted ways of "artistic" creation, and even the sort of value they favour most, seem to be significantly different from those of a literary society like ours. Consider, for instance, the oral marks that indicate in Wolof culture that a "special" discourse (i.e., a tale) is starting and so, inevitably, the people concerned are requested to adopt the displaying way of producing and perceiving its information.

Je conte
Nous t'écoutons
Il était une fois
Cela est arrivé
Quand c'est arrivé étais-tu présent?
Parle je t'écoute

In oral cultures, the displaying attitude goes further than in literate societies. There is first the rhythm to mark the passage from one communicative situation to another and to help in opening up the ways of processing information in this way. But rhythm itself has some kind of content value which can also be displayed and valued. From this point of view, Senghor (1964) has this to say:

Qu'est-ce le rythme? C'est l'architecture de l'être, le dynamisme interne qui lui donne forme, le système d'ondes qu'il émet à l'adresse des Autres, l'expression pure de la Force Vitale. Le rythme c'est le choc vibratoire, la force qui, à travers le sens, nous saisit à la racine de l'être. Il s'exprime par les moyens les plus matériels, les plus sensuels: lignes, surfaces, couleurs, volumes en architecture, scuplture et peinture; accents en poésie et musique; mouvements dans la danse. Mais ce faisant, il ordonne tout ce concret vers la lumière de l'esprit. (pp. 211-212).

Senghor is definitely not an illiterate person; therefore, this passage is full of literary images we are, more or less, used to reading in our type of society. But it is not clear to me 
wether it is possible to understand fully the real meaning of the passage unless one has had the privilege of hearing and seeing Senghor himself speaking parts of his own literary production. It is only then that one understands some particularly obscure expressions of this text like the last one: "[le rythme] ordonne tout ce concret vers la lumière de l'esprit." I can assure you, rhythm does just that when Senghor is performing!

Rhythm, however, is not the only difference. The symbolic nature of oral languages is also very concrete and, therefore, able to be displayed as well. Let us read Senghor once again:

L'oeuvre d' art nègre exprime, par nature, une ideé ou sentiment-image: un symbole. (...) L'image naît de la force de suggestion du signe employé: du signifiant. Car l'image ici n'est pas une image-équation, mais ine image-analogie, où le mot suggère beaucoup plus qu'il ne dit. Le tour de force est d'autant plus aisé que les langues africaines sont des langues concrètes, dont tous les mots, par leur racines sont chargés d'un sens concret émotif. Au-delà du sigifiant, il faut toujours voire le signifié. ${ }^{28}$

I do think that this sort of metaphoric text can only give us an intuitive notion of the representations that are culturally disseminated in some oral cultures; we cannot pretend to achieve more in this paper.

On the other hand, it does not seem the place here to give an exhaustive account of the current representations that exist in our cultural environment; it is a topic for an extended paper in its own right. However, it may be worthwhile to try a sketchy outline of what constraints we are subjected to by our own representational world in this domain, and thus come to realize that some attitudes, activities and what have you, that seem perhaps to be quite "natural" for us, are really cultural representations which differ from those we considered above in substantial ways.

I will summarize here what Pratt (1977) understood as "preparatory conditions" in the typical speech act theory trend she favoured. From our present cognitive point of view, they can be re-interpreted as representations we all have when we face the literary phenomenon.

She starts by quoting Ohman (1971), who said that

... our readiness to discover and dwell on the implicit meaning in works of literature -and to judge them important- is a consequence of our knowing them to be literary works (p.116),

and then proceeds to describe the representations that build up this knowledge:

First of all, we have the representation that the text was composed in writing and that it is definitive. This representation is composed by a structure of the following subrepresentations: the writer had time to plan and prepare his utterance and to correct it; therefore, we assume that the text is free from gross randomness -it is a satisfactory version. This representation is also formed by another subset of representations: we believe that the text will be worthwhile and because of it, we accept that it may be longer and more difficult 
to decipher. We also have the representation that the work passed through a process of selection (publishers, editors, critics, reviewers, etc.).

Like the masters of ceremonies, these literary judgers ratify the speaker on our behalf and request our attention on his behalf, with the obvious difference that the role of master of ceremonies is mainly symbolic, while that of editors, publishers and critics is very real indeed (p. 119).

This last representation gives us some confidence as to the social value ascribed to a given piece of written discourse. That is to say, we not only hope for the fulfilment of our expectancies, but we also implicitly accept the classification of the work we read given by those selection devices our culture provides. This is what I think Traugott (1976) had in mind when she stated that the notion of genres and subgenres was a set of appropriate conditions. The extent of our knowledge on these matters depends of course on our learning the social coordinates that govern a cultural background. I can imagine that the general representations (novels, theatre, poems, etc.) are quite well disseminated in our own cultural tradition, whereas some more refined classifications depend on a more specific learning which not every member of our society is able to achieve.

Summing up, one can say that we have the social representation of a speech situation in which the speaker has an unique access to the floor, but we know that this access is not free. He must make it worthwhile for us. And here lies the reason for displaying the text in one way or another so that we can value it and accept our momentary relinquishing of the floor.

\section{The implementational level of analysis}

This level is difficult to circumscribe for the following reason: in literature, the material implements, i.e., the written texts, or even the books themselves, are not considered literary components of the artistic phenomenon. It would be very strange if someone insisted on including the description of the material aspects of a text (font, length, colour, etc.) or of the object we call book, (covers, pages, weight, etc.) in a literary research paper . Yet, there is much to say about the role that printing and editing have in the representation of literature in our culture. I do not know if my own private representations of literature can be generalized; for me at least, this representation includes, as one of its constituent parts, images of well furnished libraries, handsome volumes, and cheap pocket editions awaiting to be admired and used by eager readers and other book lovers. I have deliberately made a distinction between the "admiration" that books produce, and the "use" we make of them. I said above, though, that in reading literature we process the information so that we may admire or otherwise value the messages we interpret. In this, I see a close relationship with the admiration that books, as physical objects, often produce. Very seldom is a book, in the material sense of the term, an artistic object by itself. The admiration we feel in front of a library full of books might come from our representation of the thousands of possibilities the books have in them to make us appreciate and value what others have either created or 
appreciated and valued before us. ${ }^{29}$ In cognitive science there is, however, a well entrenched belief in concentrating research almost exclusively on the analysis of computational structure, with little attention being paid to the description of the media where this structure is implemented. ${ }^{30}$ This might be a bad habit, as Hutchins, for one, thinks:.

What is the implementational level for the (...) system as a whole is the computational level for the people who operate the tools of the system. The material means in which the computation is actually performed are implementational details for the system, but they set the task constraints on the performance (...). (Id., 51)..

\section{Concluding remarks.}

In this paper I have attempted to offer an integrated view of the cognitive approach to the cultural concept of literature. As you may have noticed, very little (if anything!) is revolutionary or even new in the representational structure that forms my own picture of the world. What is new, and I think very interesting, is the way we may look at these concepts from now on. There seems to be a possibility of starting from below and perhaps reaching the skyhooks from which these concepts have been hanging until now. As Sperber (1992) believes,.

[Les sciences cognitives] ne se sont pas developpées autour d'une découverte empirique; elles n'ont d'ailleurs pas à ce jour engendré de découverte majeure. Elles ne se sont pas non plus developpées autour d'une nouvelle méthode; leur méthode est éclectique, et la seule nouveauté importante qu' elle comporte -l'utilisation de simulations sur ordinateurest loin d'être un usage général dans le domaine. Non, le point de départ et le pivot des sciences cognitives, c'est une réponse nouvelle au vieux problème des rapports entre l'âme et le corps (p.400). (My italics)..

It is true that RT in this context is sufficiently coherent and explicit to begin to analyze some of the communicative aspects of this cultural phenomenon with a fair degree of success. These aspects of art, however, still need much work before we can create a workable theory which, according to my present point of view, could well go in some of the directions I have only outlined here.

\section{Notes.}

1. Clearly, $I$ am saying all this somewhat tongue in cheek. However it is interesting to note in this respect that one of the authors of the theory, frequently annoyed by such questions, complains that the theory often interests "the wrong kind of people."

2. The full title of the book where RT is deployed is Relevance: Communication \& Cognition

3. This does not mean that I believe that "literature" is not a communicative phenomenon that has some cognitive consequences. On the contrary, and as such, RT is immensely useful as a 
means to explore some of its effects. What I am saying is that if one is able to integrate this RT explanation in a wider world view, we might achieve a better all-round vision of the whole phenomenon.

4. As far as I know, their flaws have been pointed out by Boyer (1990). In any case, I'm not talking here of the distinction between the so-called primitive and modern minds, which is a surprising side-effect of the current notion in cognitive studies that attributes cognition only to human minds and not to global socio-cultural systems (Cfr., Hutchins, 1996:354). What I am trying to do here is merely to give a sketch of a (likely?) evolutionary history of human minds.

5. There are thousands of papers, articles, books, etc. stating similar ideas. A very interesting one is Dennett (1995)

6. Sperber \& Wilson (1986) speak of these factual assumptions as stored directly in human minds (as, for instance $P$ ), and oppose them to other ways of storing assumptions (for instance: $I$ believe that $P$, or $P$ is true, etc).

7. In order to be exact, perhaps one should say, very natural and very cultural.

8. Although it does not correspond strictly to this level, as one can easily infer from the description of the requirements

9. However, I am not altogether happy with the definition of meaning as a set of truth conditions, for I don't think that this comparison covers the whole notion; but since this is not a paper on the meaning of meaning, we will not pursue the question further. Of course, the same misgivings haunt me in the case of desires, although it might be a good start to pretend we accept this description without doubts. In this I follow Sperber's idea that incomplete representations help one to build world views and extend knowledge. (See above, p.2).

10. It may be objected that there are representations of literature that seem to be more extended than others. For instance, the idea that literature is to be found in texts is a very popular one; as a consequence, the author of the text is therefore considered the creator of (a work of) literature. We will try to characterize the dissemination of some representations across a given social tissue and see if we can establish relationships between individual minds and socially distributed systems of representations.

11. This for some levels is absolutely true. The problem is when inadvertently one assumes that certain (structure of) hypothesis are manifest for everybody and one uses this as a basic element in the construction of a theory.

12. Sperber (1996) humorously shows that, from a structuralist point of view, one could argue that Hamlet and Red Riding Hood have exactly opposite deep structures!

13. Cfr., Chomsky (1992)

14. Cfr., Sperber \& Wilson (1986) and, notably, Pilkington (1992)

15. Certain African oral cultures, for instance, distinguish between the "angular word" and the "round word." The angular word, they claim is the one that hurts if it hits you -what we would call in our culture the "normal" (?!) discourse; the "round word" however, having no sharp edges, can never hurt you -we would call it poetic, or literary discourse. Cfr. Calame-Griaule $(1965,1970)$. Note that in both cultures, there is a sharp distinction in the types of objects that we now call discourse in our culture or words in those African societies; this could naturally mean, that this distinction had a natural cause we must discover.

16. See note 11

17. Cfr., Barkow, Cosmides \& Tooby (1992) -not to mention Chomsky in almost all of his work. 
18. Guijarro $(1984,1993)$

19. It is very difficult for me to decide at what point a certain element that can become a candidate to be considered a premise in an inferencing process turns into a coded element that triggers an immediate response. For example: the first time I turned off the ignition of my newly acquired car and it started to whistle a traditional cowboy song, I had to make all sorts of inferencing processes in order to know what the whistling was about. It took me at least a minute to do the right sort of reasoning. Now, as soon as I hear the whistle, I know I have left the lights on, and I automatically turn them off. It has become a coded signal for me! Hutchins (1996:2378) says something that could be of interest in this aspect:

Meanings seem to be in the messages only when the structures with which the message must be brought into coordination are already reliably in place and taken for granted. The illusion of meaning in the message is a hard-won social and cultural accomplishment. (My italics).

20. say peculiar because I am not aware that any other living organism uses its mental powers to direct information processing in that way.

21. In fact, some researchers, believe that "Any higher mental function (...) was social at some point before becoming an internal, truly mental function. It was first a social relation between two people" (Vygotsky, quoted in Hutchins (id:283))

22. Cfr., Sperber \& Wilson, 1986:

23. Cfr. Bruner, id.: 51

24. See Deirdre Wilson's miméographed class notes on Semantic Theory, for instance

25. Sperber, 1984: p.77

26. Cfr., Díaz-Plaja, 1984: 29

27. Kesteloot, Liliane \& M'Body (1983)

28. Quoted by Adiaffi (1983), p.20

29. Pratt makes a very interesting remark in this respect. She acknowledges the fact that books bear with them at least the message that another person, on top of the author, considered the book worth it. This makes it different from orators in street corners and writers of side-walk poetry. They have to win their audience by themselves, while in institutionalized literature as it is implemented in books, this is done by a host of other people who as I said above, considered it important enough to have published, reviewed and sold in book shops. As she says: "an utterance which does not pass trough this process (whether because it was not submitted or because it was rejected) is not a work of literature" (p.120-1)

30 . We have heard thousands of times that what is important is the program, not the types of machines that can run it.

\section{Works cited}

Adiaffi, J. "Les mâtres de la parole." Magazine Littéraire 195 (1980).

Andler, D., ed. Introduction aux sciences cognitives. Paris: Gallimard, Folio 179 Essais, 1992.

Barkow, J., Cosmides, L. \& Tooby, J., eds. The Adapted Mind: Evolutionary Psychology and the Generation of Culture. Oxford: O.U.P., 1992.

Berlyne, D. Aesthetics and Psychobiology. New York: Appleton Century-Crofts, 1971.

Boyer, P. Tradition as Truth and Communication. A Cognitive Description of Traditional Discourse. Cambridge: C.U.P. 
Brown, G. \& Yule, G. Discourse Analysis. Cambridge: C.U.P., 1983.

Bruner, J. Acts of Meaning. Cambridge, Mass.: Harvard U.P., 1990.

Calame-Griaule, G. Ethnologie et langage: La parole chez les Dogons. Paris: Gallimard, 1965. . "Pour une étude ethnolinguistique des littératures orales Africaines." Langages 18 (1970).

Chomsky, N. "Explaining language use." Philosophical Topics 20 (1992).

Dennett; D. Darwin's Dangerous Idea. London: The Penguin Press, 1995.

Diaz-Plaja, G. Ensayos sobre la comunicación cultural. Madrid: Espasa Calpe (Austral), 1984.

Fodor, J. The Modularity of Mind. Cambridge, Mass.: MIT Press, 1983.

Fraser, C. \& Gaskell, G., eds. The Social Psychological Study of Widespread Beliefs. Oxford: Clarendon Press, 1990.

Guijarro, J.L. "¿Literatura? Y eso, ¿qué es?." Gades 12 (1984).

"Comunicación literaria." Actas del primer encuentro interdisciplinar sobre retórica, texto y comunicación, Cádiz, Servicio de publicaciones de la UCA., 1993.

Hollis, M. \& Lukes, S., eds. Rationality and Relativism. Oxford: Basil Blackwell, 1982.

Horton, R. "Tradition and modernity revisited." In Hollis \& Lukes, eds., 1982.

Hutchins, E. Cognition in the Wild. Cambridge, Mass.: MIT Press, 1996.

Kesteloot, L. \& M'Body, C. Contes et mythes Wolof. Dakar: Novelles ëditions Africaines, 1983. Ohman, R. "Speech acts and the definition of Literature." Philology and Rethoric 4 (1971).

Papineau, D. Reality and Representation. Oxford: Basil Blackwell, 1987.

Pilkinton, A. "Poetic effects." Lingua 87(1/2) (1992).

Pratt, M-L. Toward a Speech Act Theory of Literary Discourse. Bloomington, Indiana: I.U.P, 1997.

Rivière, A. Razonamiento y representación. Madrid: Siglo XXI, 1986.

Senghor, L. Liberté I: Négritude et Humanisme. Paris: Le Seuil, 1964.

Simon, H. The Sciences of the Artificial. Cambridge, Mass.: MIT Press, 1981.

Sperber, D. "Anthropology and psychology: towards an epidemiology of representations" (Malinowki Memorial Lecture, 1984). Man (New Series) 20 (1985). . "The epidemiology of beliefs." In Fraser \& Gaskell, eds., 1990.

1992. . "Les sciences cognitives, les sciences sociales et le matérialisme. In Andler, ed., . La contagion des idées. Paris: Odile Jacob, 1996.

Sperber, D. \& Wilson, D. Relevance: Communication and Cognition. Oxford: Basil Blackwell, 1986 (second edition, 1995).

Traugott, E. "Generative Semantics and the concept of Literature." Journal of Literary Semantics 2 (1973). 